\title{
Temperature Inversions, Meteorological Variables and Air Pollutants and Their Influence on Acute Respiratory Disease in the Guadalajara Metropolitan Zone, Jalisco, Mexico
}

\author{
Hermes U. Ramírez-Sánchez, Mario E. García-Guadalupe, Héctor H. Ulloa-Gódinez, \\ Ángel R. Meulenert-Peña, Omar García-Concepción, Jaime Alcalá Gutierrez, \\ Sarahi J. Lizarraga Brito
}

Department of Physics, Institute of Astronomy and Meteorology, University Center of Exact Sciences and Engineering (CUCEI), University of Guadalajara, Guadalajara, Mexico.

Email: almasgemelas68@hotmail.com

Received June $4^{\text {th }}, 2013$; revised July $9^{\text {th }}, 2013$; accepted August $2^{\text {nd }}, 2013$

Copyright (C 2013 Hermes U. Ramírez-Sánchez et al. This is an open access article distributed under the Creative Commons Attribution License, which permits unrestricted use, distribution, and reproduction in any medium, provided the original work is properly cited.

\begin{abstract}
The presence of temperature inversions (TI), concentration of air pollutants (AP) and meteorological variables (MV) affect the welfare of the population, creating public health problems (acute respiratory diseases ARDs, among others). The Guadalajara Metropolitan Zone (GMZ) experiences high levels of air pollution, which associated with the presence of temperature inversions and meteorological variations is conducive to the incidence of ARDs in children. The aim of this work is to evaluate the TI, MV, AP and their influence on the ARDs in children under five years in the GMZ from 2003 to 2007. In this period, the moderate and strong TI are the most frequent presenting from November to May. The AP shows a variable behavior during the year and between years, with the highest concentration of particles less than 10 microns $\left(\mathrm{PM}_{10}\right)$, followed by ozone $\left(\mathrm{O}_{3}\right)$, nitrogen dioxide $\left(\mathrm{NO}_{2}\right)$, nitrogen oxides $\left(\mathrm{NO}_{\mathrm{X}}\right)$, carbon monoxide $(\mathrm{CO})$ and sulfur dioxide $\left(\mathrm{SO}_{2}\right)$, the most affected areas are the southeast of the GMZ. Annual arithmetic mean is 213,510 \pm 41,209 ARDs consultations. The most important diseases are acute respiratory infections $(98.0 \%)$, followed by pneumonia and bronchopneumonia (1.1\%), asthma and status asthmaticus $(0.5 \%)$ and streptococcal pharyngitis and tonsillitis $(0.4 \%)$. Months with most inquiries were from October to March, mainly in the southeast, south and center of the city, coinciding with high levels of AP. Statistical analysis shows that the TI have significant correlation with ARDs in three years, temperature (Temp) in two, relative humidity (RH) in two, wind speed (WS) in three, wind direction (WD) in two, while that air pollutants $\mathrm{NO}_{\mathrm{X}}$ and $\mathrm{NO}_{2}$ showed significant correlation with ARDs throughout the period. $\mathrm{CO}$ and $\mathrm{SO}_{2}$ showed significance in two years, while the $\mathrm{PM}_{10}$ and $\mathrm{O}_{3}$ in one.
\end{abstract}

Keywords: Temperature Inversions; Meteorological Variables; Air Pollutants; Acute Respiratory Diseases

\section{Introduction}

A major problem in large cities around the world is the environmental degradation, where air pollution generates significant risks and impacts on the welfare of the population. Elevated indices of air pollutants emitted into the atmosphere cause problems in the long and medium term (global warming, climate change, etc.), in local and regional zones, causing public health problems, particularly respiratory and cardiovascular diseases [1].

Air pollution is of great importance from events such as Meuse Valley (Belgium) in 1930, Donora (Pennsylvania, USA) in 1948 and London in December 1952 [2, 3]. These events led to an increase in morbidity and mortality, showing that levels of air pollution are causally associated with an increase in premature deaths. This evidence led to the adoption of policies for air pollution control in Western Europe and the United States that have managed to reduce it. Also, several studies have reported that the most vulnerable groups are children and seniors, with a high incidence of morbidity and mortality $[1,4,5]$.

However, some of the effects observed for some pol- 
lutants and specific mechanisms are not sufficiently studied in relation to the influence of temperature inversions and meteorological variables.

Temperature Inversions (TI) are changes in the normal tendency of air to cool with altitude; when there is a TI, the temperature increases with altitude in the troposphere. This temperature increase may occur from the surface to a certain height $[3,6,7]$. TI are natural phenomena that may occur at any time and day of the year, ending when the sun's rays reach maximum or when wind speed exceeds $20 \mathrm{~km} / \mathrm{h}$. Natural phenomena not presenting a risk to human health, however, can become dangerous in an urban area where the warm air layer prevents the development of disperse contaminants. This situation is exacerbated in the presence of air masses of high pressure that promote a temperature inversion for several days. Under these conditions, air pollutants are concentrated near the surface, reaching values harmful to human health $[8,9]$. It is therefore possible that under certain meteorological conditions IT intensify the accumulation of pollutants in the air.

Health biodiversity are influenced by environmental conditions, atmospheric pollution and biological environment they occupy. Meteorological variables directly affect the behavior of pollutants in the atmosphere, in particular wind speed, atmospheric stability and variations in humidity and temperature. High temperature may decrease the metabolism and allow the emergence of digestive disorders, low temperature activates the metabolism but bring respiratory problems. Meanwhile, it is known that the rain worsens rheumatic problems and environmental dryness leads to increased infections. Atmospheric pressure is related to the geographical location of the area (higher in coastal regions), which can affect blood pressure. Sunlight combats depression, osteoporosis and rickets, cold days, wet or cloudy favor the appearance of nervous disorders, suicide, epileptic seizures, insomnia and embolism. Also, fog worsens bronchitis while improving asthma. Heat waves are associated with cardiovascular and respiratory diseases, among others. Moreover, the frequency of warm meteorology, temperature inversions and natural fire, may reduce air quality in urban areas [10].

Meanwhile, the atmospheric stability of the boundary layer is very important because it determines the intensity of the turbulence of the wind that may influence the transport of water vapor, carbon dioxide, heat and pollutants. Therefore, surface pollutants may be dispersed to upper layers of the atmosphere or get caught in urban areas just above the surface. The atmosphere is stable when an air parcel is vertically moved back to its original position, that is, opposed to the original vertical movement. When the atmosphere is stable near the surface, pollution emissions accumulate to remain trapped and unable to disperse vertically $[2,6,7]$.

The aim of this work was to evaluate the presence of temperature inversions, meteorological variables, concentration of air pollutants and their influence on acute respiratory diseases in children in the Guadalajara Metropolitan Zone (GMZ).

\section{Materials and Methods}

The methodology consisted primarily in gathering information from the temperature inversions (TI), meteorological variables (MV) (temperature, humidity, pressure, wind direction and speed, etc.) and the concentrations of major air pollutants (AP): carbon monoxide $(\mathrm{CO})$, nitrogen dioxide $\left(\mathrm{NO}_{2}\right)$, nitrogen oxides $\left(\mathrm{NO}_{\mathrm{X}}\right)$, ozone $\left(\mathrm{O}_{3}\right)$, sulfur dioxide $\left(\mathrm{SO}_{2}\right)$ and particulate matter less than 10 microns $\left(\mathrm{PM}_{10}\right)$ in the Guadalajara Metropolitan Zone from 2003 to 2007. Later databases were constructed for each of these variables. With the Geographic Information Systems (GIS) we analyzed the spatiotemporal behavior of each one of them to describe their variations. At same time information was accessed from the medical services of the Jalisco Health Secretariat (JHS) to identify and quantify acute respiratory diseases (ARDs) that had a higher incidence in the GMZ from 2003 to 2007. Also, there was a database of the spatiotemporal distribution of the same in the GMZ in the period analyzed by GIS.

Later correlations were established between TI vs AP, TI vs ARDs, MV and ARDs, AP vs ARDs and a multivariate analysis of TI, MV and AP vs ARDs from 2003 to 2007 in the GMZ. With the results of the correlations between variables we proposed the most affected areas, the most vulnerable populations and suggested preventive measures for optimal response in the presence of temperature inversion events, extreme values of meteorological variables, high concentrations of air pollutants and increasing the number of ARDs as a result of TI events, MV and AP.

\section{Results}

\subsection{Behavior of Temperature Inversions (TI) in the GMZ from 2003 to 2007}

Figure 1 shows the percentages of thermal inversions per year, 2005 showed the maximum value of $82.82 \%$ of days with TI, and 2007 the minimum with $67.97 \%$. Regarding the annual average intensity, 2005 showed the maximum gradient $3.79^{\circ} \mathrm{C}$, and 2004 the minimum with $2.85^{\circ} \mathrm{C}$ (Figure 2). The maximum annual average thickness was for 2005 with $201.05 \mathrm{~m}$, and the minimum 2007 with $141.7 \mathrm{~m}$ (Figure 3). The time break of maximum annual average was $10: 36 \mathrm{~h}$ in 2005 and the minimum at 9:26 h in 2004 (Figure 4). 


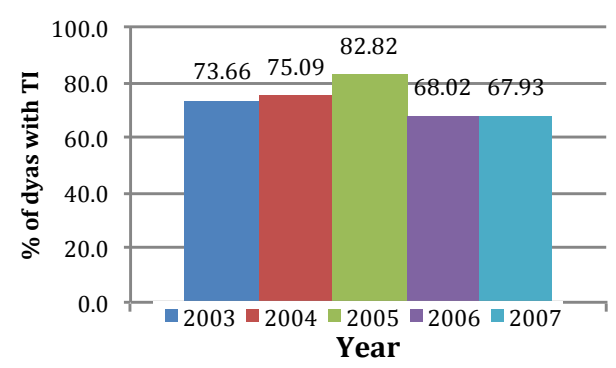

Figure 1. Annual percentage of days with TI in the GMZ.

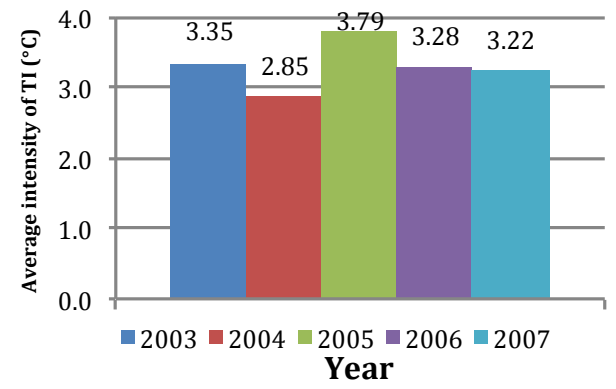

Figure 2. Annual average of TI intensity in the GMZ.

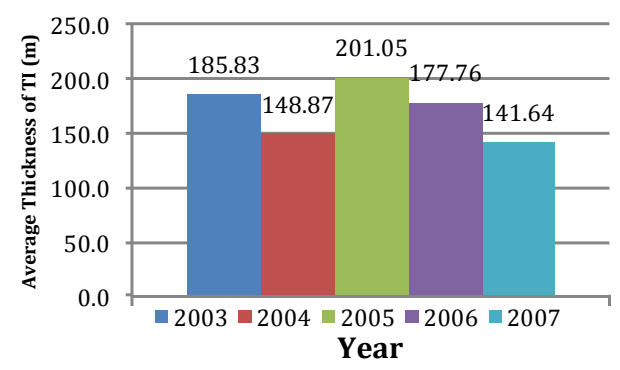

Figure 3. Annual average thickness of TI in the GMZ.

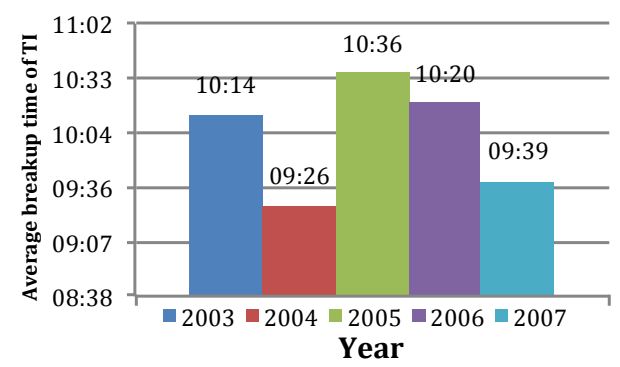

Figure 4. Annual average time rupture of TI in the GMZ.

Monthly analysis shows that the number of TI is larger during the winter and spring months (November to May) until rainstorms start (Figure 5). Meanwhile monthly average intensities show the same behavior as the frequency and the months of November to May had the highest intensities in the temperature gradient of thermal inversions (Figure 6). The thickness of the TI presents very heterogeneous values, although there was a trend of increase from 2003 to 2005 and decline from 2005 to 2007 , in monthly terms there seems to be not well-de- fined pattern and values are very homogeneous in all months (Figure 7). Meanwhile the monthly breaking times show that the months of November to May showed longer rupture times (Figure 8).

During the period 2003-2007 the maximum variation range of TI intensity occurs in the months of November to May, while in rainy months the range is reduced. The maximum thicknesses are between 100 and $1000 \mathrm{~m}$, while the minimum range between 30 and $100 \mathrm{~m}$.

To classify TI intensities the following scale was used:

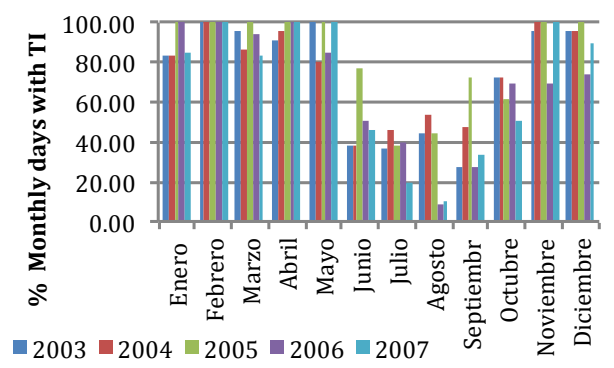

Figure 5. Monthly percentage of days with TI in the GMZ.

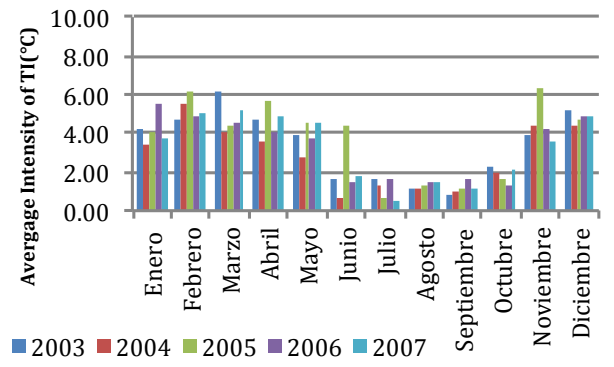

Figure 6. Monthly average of TI intensity in the GMZ.

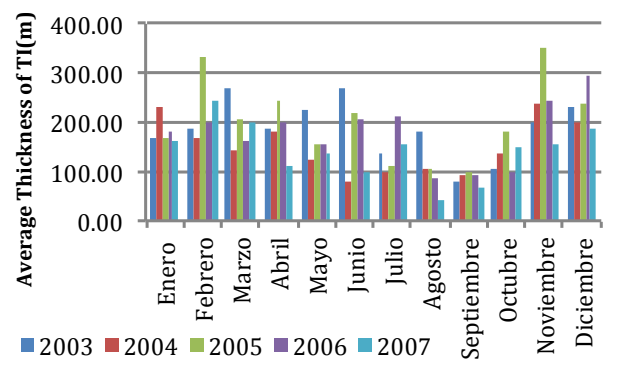

Figure 7. Monthly average thickness of IT in the GMZ.

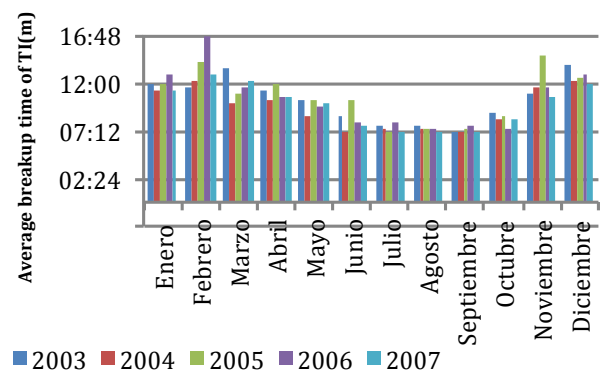

Figure 8. Monthly average time rupture of IT in the GMZ. 
from $0.1^{\circ} \mathrm{C}$ to $1.0^{\circ} \mathrm{C}$ (very low intensity) of $1.1^{\circ} \mathrm{C}$ to $2.0^{\circ} \mathrm{C}$ (low intensity), in the range of $2.1^{\circ} \mathrm{C}$ to $3.0^{\circ} \mathrm{C}$ (low moderate intensity), between $3.1^{\circ} \mathrm{C}$ and $4^{\circ} \mathrm{C}$ (high moderate intensity) and $>4.0^{\circ} \mathrm{C}$ (strong intensity). The results show the percentages of TI intensities that were presented in the GMZ from 2003 to 2007 have a similar behavior in the five years. Prevailing temperature inversions are moderate to strong $\left(>4^{\circ} \mathrm{C}\right)$ (Figure 9). Analyzing monthly like other TI parameters the most important values are between November and May and descend in the rainy months.

\subsection{Behavior Air Pollutants (AP) (CO, $\mathrm{NO}_{2}$, $\mathrm{NO}_{\mathrm{X}}, \mathrm{O}_{3}, \mathrm{SO}_{2}, \mathrm{PM}_{10}$ ) in the GMZ from 2003 to 2007}

Results show highly variable behavior during the year and between the years analyzed. However, it was evident that the pollutant with the highest concentration is $\mathrm{PM}_{10}$, followed by $\mathrm{O}_{3}, \mathrm{NO}_{2}, \mathrm{NO}_{\mathrm{X}}, \mathrm{CO}$ and $\mathrm{SO}_{2}$. The most affected areas are the southeast of the GMZ, which has the highest records in both its maximum, averages and modes. The annual results showed that a significant percentage of days exceeded Mexican standards (Table 1).

From April to June there were high concentrations of $\mathrm{O}_{3}, \mathrm{PM}_{10}$ and $\mathrm{CO}$ while December to March showed high concentrations of $\mathrm{PM}_{10}, \mathrm{NO}_{2}, \mathrm{NO}_{\mathrm{X}}, \mathrm{CO}$ and $\mathrm{SO}_{2}$, resulting from the presence of low temperatures which prolong the duration times of temperature inversions and low humidity of the environment not allowing dispersal.

\subsection{Carbon Monoxide (CO)}

Carbon monoxide presents monthly mean concentrations below EPA standards and NOM. The average monthly mean was $1.858 \pm 0.634 \mathrm{ppm}$ and the range of values is between $0.316-4.883$ ppm (Table 2 and Figure 10). Meanwhile, monthly maximum concentrations have values above norm in most of the analyzed period, presenting peaks with values of $53.600 \mathrm{ppm}$, representing five times the norm NOM and six times the EPA, which represents population risk factors. These events are recorded in the driest period of the year (March-June) just before precipitation. The average value of the monthly maximum was $8.844 \pm 5.310 \mathrm{ppm}$ and monthly highs range between 0.200 - 53.600 ppm (Table 2 and Figure 11). Most affected areas are the central and southeastern of GMZ, however, the pollution generated by the $\mathrm{CO}$ in the GMZ is considered significant only at times of peak levels.

\subsection{Nitrogen Dioxide $\left(\mathrm{NO}_{2}\right)$}

Monthly average concentrations show values below the norm NOM, but sometimes they are near or above the EPA standard (0.05 and $0.10 \mathrm{ppm})$. The mean monthly average was $0.034 \pm 0.010 \mathrm{ppm}$ and the range of values is between $0.006-0.089$ ppm (Table 2 and Figure 12).

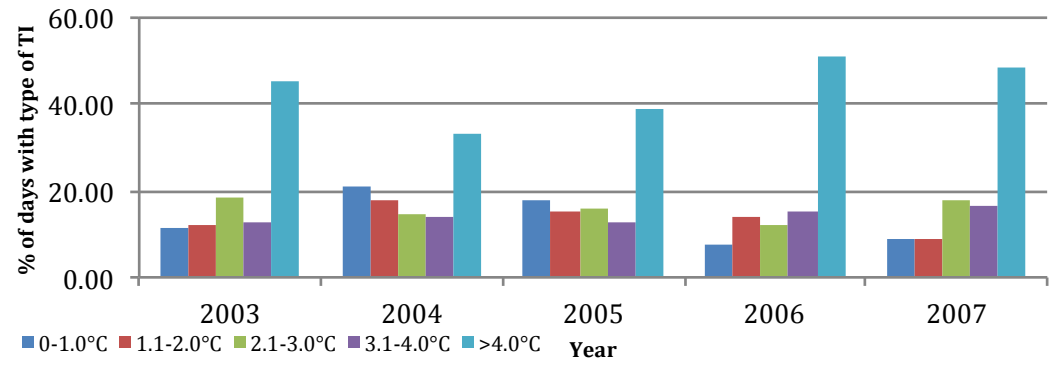

Figure 9. Percentages of TI intensities in the GMZ.

Table 1. Number of days out of standard for each pollutant in Guadalajara metropolitan zone.

\begin{tabular}{cccccccc}
\hline Parameter & Limits values & Acute Exposure & 2003 & 2004 & 2005 & 2006 & 2007 \\
\hline Ozone $\left(\mathrm{O}_{3}\right)$ & $0.11 \mathrm{ppm}(1 \mathrm{Hour})^{1}$ & once a year & 71 & 49 & 66 & 89 & 87 \\
Nitrogen Dioxide $\left(\mathrm{NO}_{2}\right)$ & $0.21 \mathrm{ppm}(1 \mathrm{Hour})^{2}$ & once a year & 5 & 6 & 13 & 14 & 24 \\
Carbon Monoxide $(\mathrm{CO})$ & $11 \mathrm{ppm}(8 \mathrm{Hours})^{3}$ & once every 3 years & 11 & 8 & 3 & 3 & 0 \\
Sulfur Dioxide $\left(\mathrm{SO}_{2}\right)$ & $0.13 \mathrm{ppm}(24 \mathrm{Hours})^{4}$ & once a year & 0 & 0 & 0 & 0 & 0 \\
$\begin{array}{c}\text { Particulate matter less than } \\
10 \text { microns }\left(\mathrm{PM}_{10}\right)\end{array}$ & $120 \mathrm{mg} / \mathrm{m}^{3}(24 \mathrm{Hours})^{5}$ & once a year & 115 & 94 & 93 & 101 & 47 \\
\hline
\end{tabular}

${ }^{*} \mathrm{CO}$ values but not in all cases occurred in 8 hours continue if exceeded at certain times of the day recorded the regulations. ${ }^{* *} \mathrm{The}$ values of $\mathrm{PM}_{10}$ and $\mathrm{SO}_{2}$ but not all were presented in 24 continuous hours, if exceeded at certain times of the day recorded the regulations. ${ }^{1} \mathrm{NOM}-020-\mathrm{SSAI}-1993$, ${ }^{2} \mathrm{NOM}-023-\mathrm{SSAI}-1993$, ${ }^{3}$ NOM-021-SSAI-1993, ${ }^{4}$ NOM-022-SSAI-1993, ${ }^{5}$ NOM-025-SSAI-1993. 

Acute Respiratory Disease in the Guadalajara Metropolitan Zone, Jalisco, Mexico

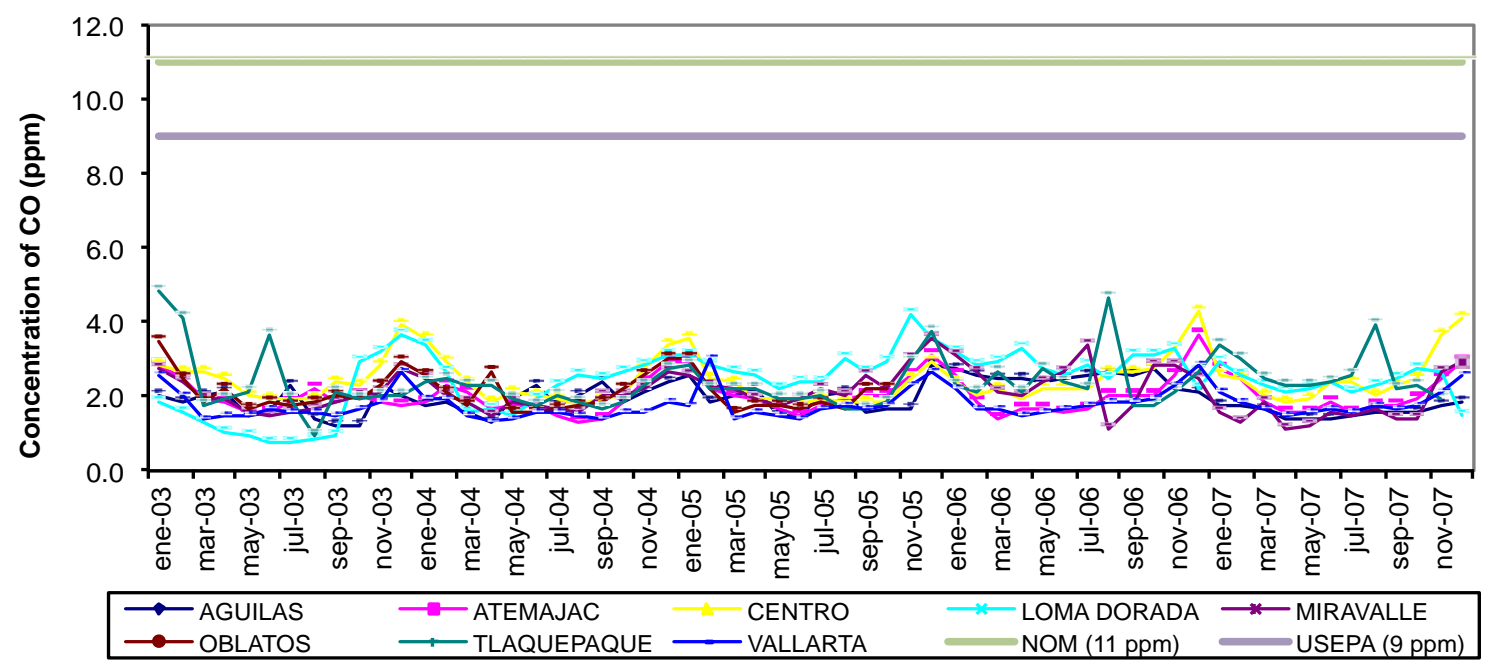

Figure 10. Time series of monthly averages of CO in the GMZ.

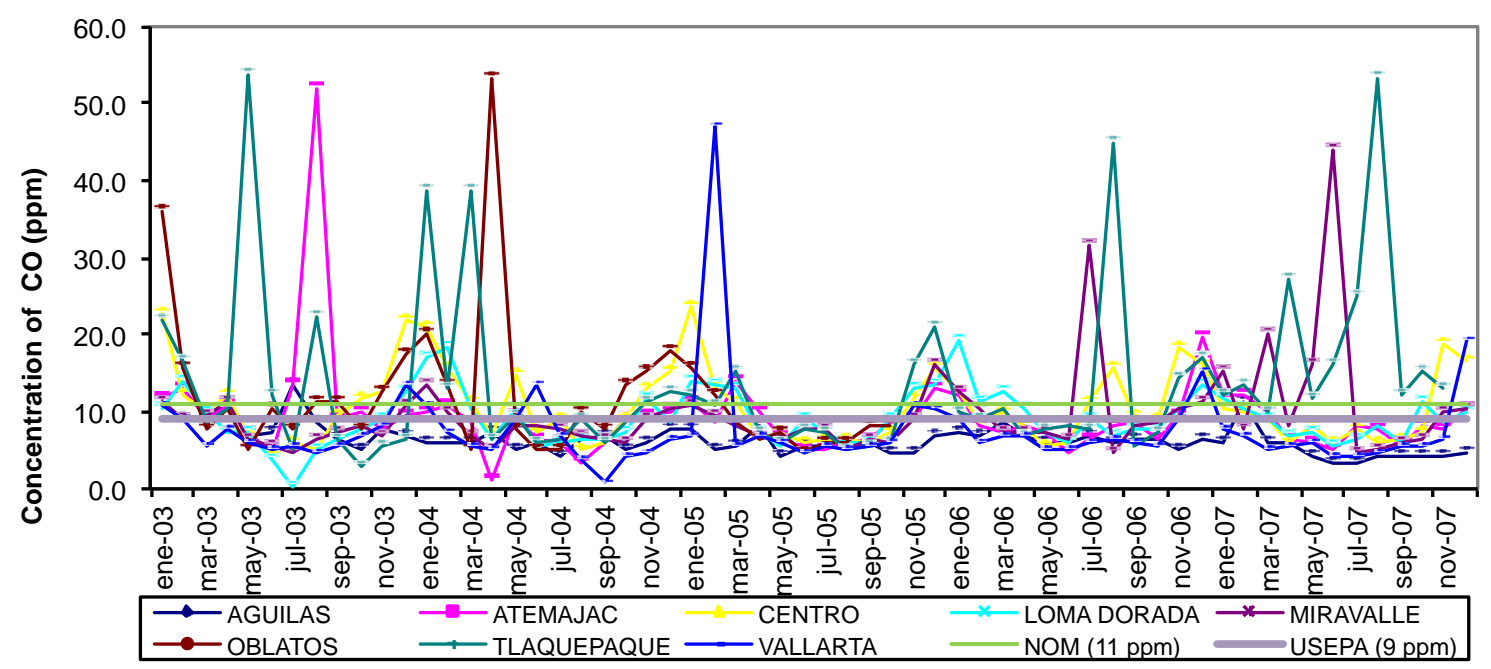

Figure 11. Time series of monthly maximum CO in the GMZ.

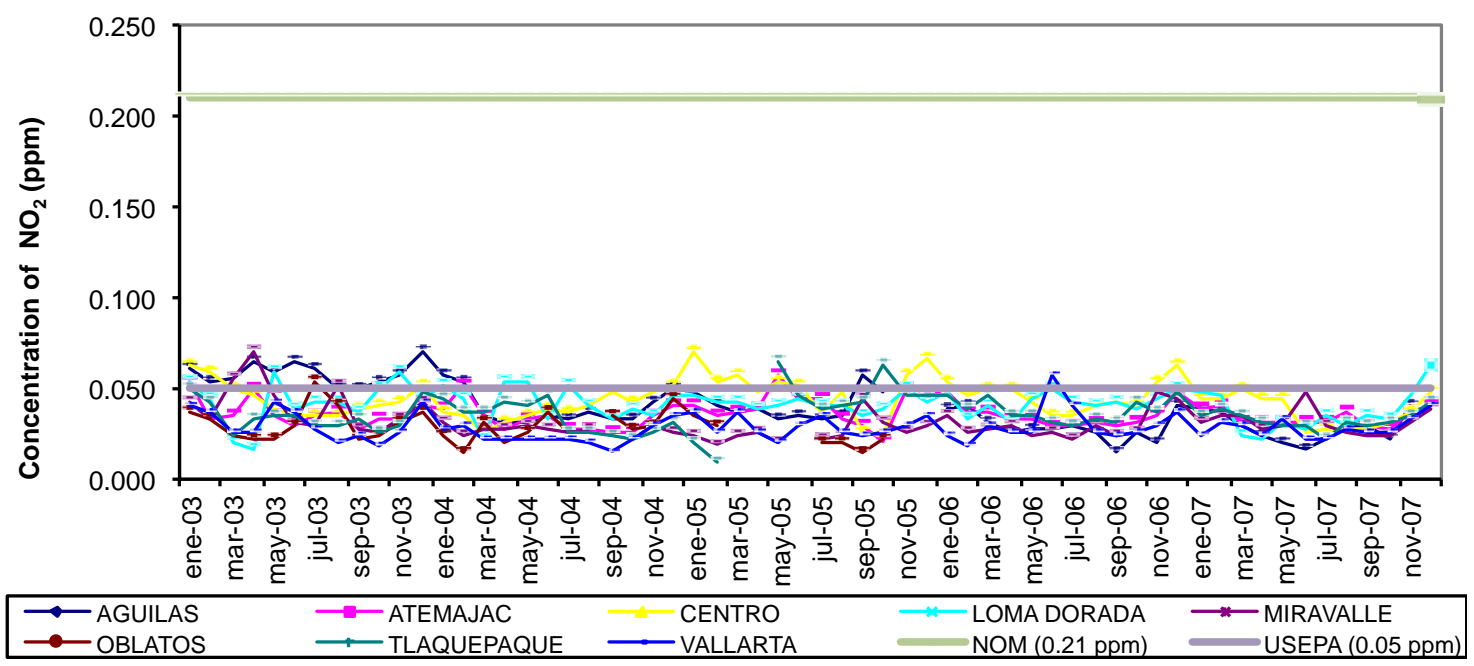

Figure 12. Time series of monthly averages of $\mathrm{NO}_{2}$ in the GMZ. 
Table 2. Mean, standard deviation, maximum and minimum of the means and maximums of air pollutants in the GMZ from 2003-2007.

\begin{tabular}{|c|c|c|c|c|c|c|c|c|}
\hline & \multicolumn{4}{|c|}{ Means } & \multicolumn{4}{|c|}{ Maximum } \\
\hline & $X$ & $\mathrm{~S}$ & Maximum & Minimum & $X$ & $\mathrm{~S}$ & Maximum & Minimum \\
\hline $\mathrm{CO}$ & 1.858 & 0.634 & 4.883 & 0.316 & 8.844 & 5.310 & 53.600 & 0.200 \\
\hline $\mathrm{NO}_{2}$ & 0.034 & 0.010 & 0.089 & 0.006 & 0.118 & 0.068 & 0.526 & 0.006 \\
\hline $\mathrm{NO}_{\mathrm{X}}$ & 0.057 & 0.023 & 0.232 & 0.005 & 0.329 & 0.157 & 2.536 & 0.012 \\
\hline $\mathrm{O}_{3}$ & 0.026 & 0.008 & 0.057 & 0.008 & 0.119 & 0.037 & 0.650 & 0.008 \\
\hline $\mathrm{PM}_{10}$ & 49.778 & 18.789 & 156.006 & 8.544 & 263.197 & 104.019 & 499.900 & 37.200 \\
\hline $\mathrm{SO}_{2}$ & 0.009 & 0.005 & 0.068 & 0.001 & 0.045 & 0.049 & 0.534 & 0.001 \\
\hline
\end{tabular}

Meanwhile, monthly maximum values have significant variations from 0.000 to $0.526 \mathrm{ppm}$. Maximum concentration peaks do not present a cyclic behavior (Table 2 and Figure 13). The average value of the monthly maximum was $0.118 \pm 0.068 \mathrm{ppm}$ and the range of values is between $0.006-0.526 \mathrm{ppm}$. In this case there is no specific area where maximum values occur, it is a problem throughout the GMZ.

\subsection{Nitrogen Oxides $\left(\mathrm{NO}_{\mathrm{x}}\right)$}

The monthly average concentrations have values below the NOM, but above the EPA standard (values between 0.05 and $0.15 \mathrm{ppm}$ ). The average monthly mean was $0.057 \pm 0.023 \mathrm{ppm}$ and the range of monthly mean values is between $0.005-0.232 \mathrm{ppm}$ (Table 2 and Figure 14). The monthly maximum values have significant variations from $0.012-2.536 \mathrm{ppm}$. The maximum concentration peaks do not exhibit cyclic behavior. The maximum value of the monthly average was $0.329 \pm$ 0.157 ppm (Table 2 and Figure 15). There is no specific area where maximum values occur, it is a problem throughout the GMZ.

\subsection{Ozone $\left(\mathrm{O}_{3}\right)$}

The monthly average concentrations showed seasonal variations with a tendency to remain constant during the study period with values below the norm NOM. The mean monthly averages were $0.026 \pm 0.008 \mathrm{ppm}$ and the range of values is between $0.008-0.057 \mathrm{ppm}$ (Table 2 and Figure 16). The monthly maximums in most cases were over NOM and EPA standards and with a slight tendency to increase in recent years. Substantial variations of $0.008-0.650 \mathrm{ppm}$ in the maximum concentration peaks occur in the dry season and summer where there is more sunlight and transformation of primary pollutants to $\mathrm{O}_{3}$. The average monthly maximum was $0.119 \pm 0.037 \mathrm{ppm}$ (Table 2 and Figure 17). Most af- fected areas are the center and southeast of $\mathrm{GMZ}, \mathrm{O}_{3}$ pollution is considered moderate and represents a risk factor for the health of the population.

\subsection{Particles Less than 10 Microns $\left(\mathbf{P M}_{10}\right)$}

The monthly average concentrations have values between 8.54 and $156.01 \mu \mathrm{g} / \mathrm{m}^{3}$, with most records within the limits of EPA regulations and NOM. GMZ maintained without giving the same sample levels decline, so $\mathrm{PM}_{10}$ represents the major pollutant. The mean monthly average was $49.78 \pm 18.79 \mu \mathrm{g} / \mathrm{m}^{3}$ (Table 2 and Figure 18). The monthly maximum values are above NOM and EPA standards with a range of $37.20-500 \mu \mathrm{g} / \mathrm{m}^{3}$. Recorded values are well above the standards, which represent the main air pollutant of the GMZ. The average value of the monthly maximum was $263.20 \pm 104.02$ $\mu \mathrm{g} / \mathrm{m}^{3}$ (Table 2 and Figure 19). $\mathrm{PM}_{10}$ concentrations represent a very important problem of environmental pollution and risk factor to the health of the population throughout the GMZ, however extreme events are located in the south and southeast all year.

\subsection{Sulfur Dioxide $\left(\mathrm{SO}_{2}\right)$}

The monthly average concentrations ranged from 0.001 to $0.068 \mathrm{ppm}$. Values do not exceed EPA regulations and are far from the NOM and are constant without trend. $\mathrm{SO}_{2}$ is a pollutant of little influence on the health of the population in the GMZ.

The mean monthly average was $0.009 \pm 0.005 \mathrm{ppm}$ (Table 2 and Figure 20). The monthly maximum values during the period are above the EPA standard, but below the NOM, values ranging from $0.001-0.534 \mathrm{ppm}$. The maximum value of the monthly averages was $0.045 \pm$ 0.049 ppm (Table 2 and Figure 21). The most affected areas are the central, south and southeast areas of the $\mathrm{GMZ}$, however, $\mathrm{SO}_{2}$ concentrations are not a contaminant risk to the health of the population in the GMZ. 


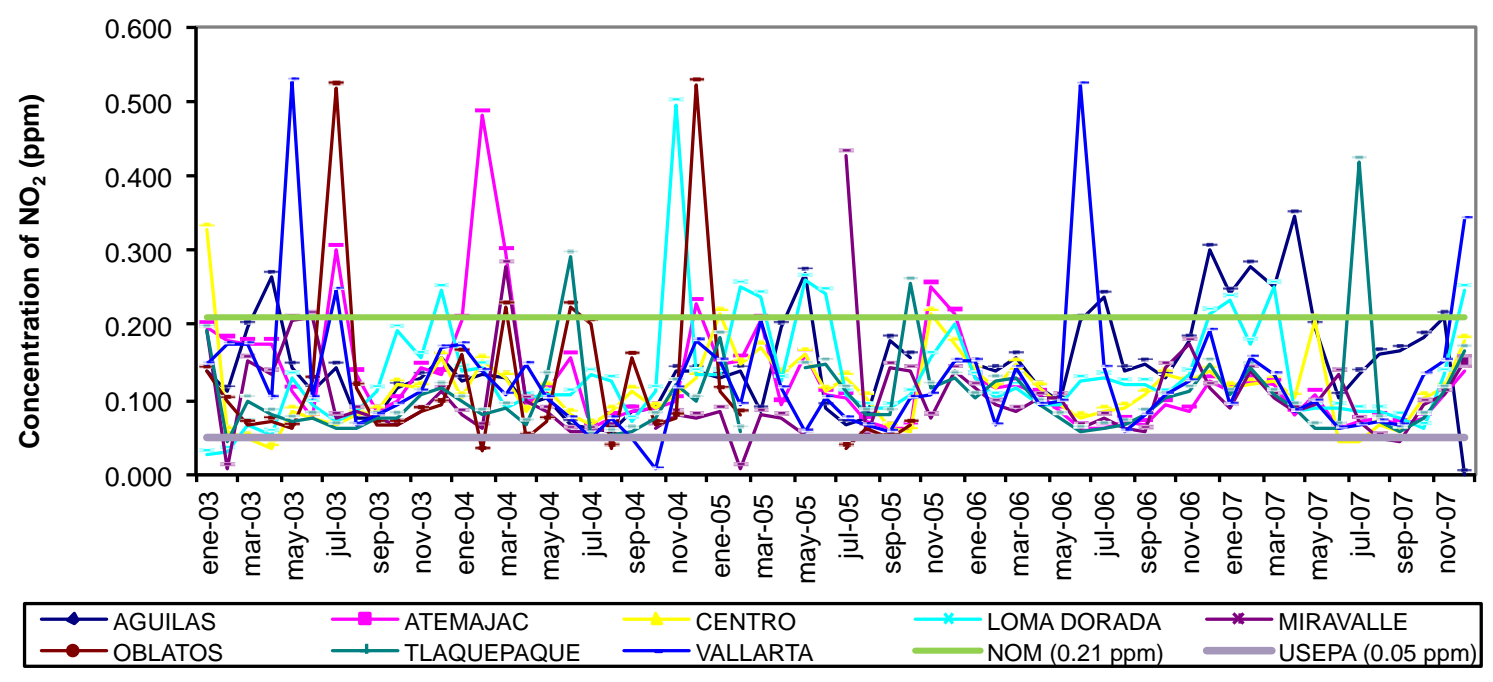

Figure 13. Time series of monthly maximum $\mathrm{NO}_{2}$ in the GMZ.

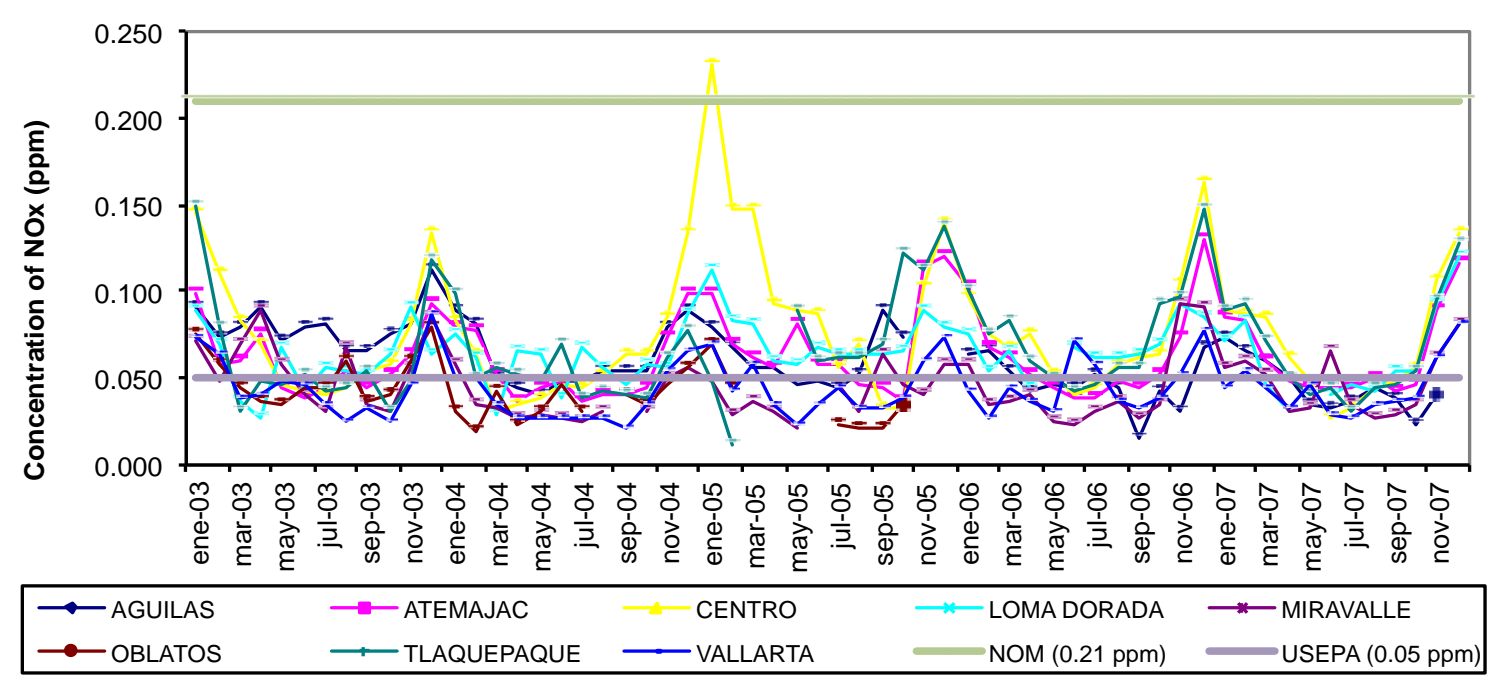

Figure 14. Time series of monthly averages of $\mathrm{NO}_{\mathrm{X}}$ in the GMZ.

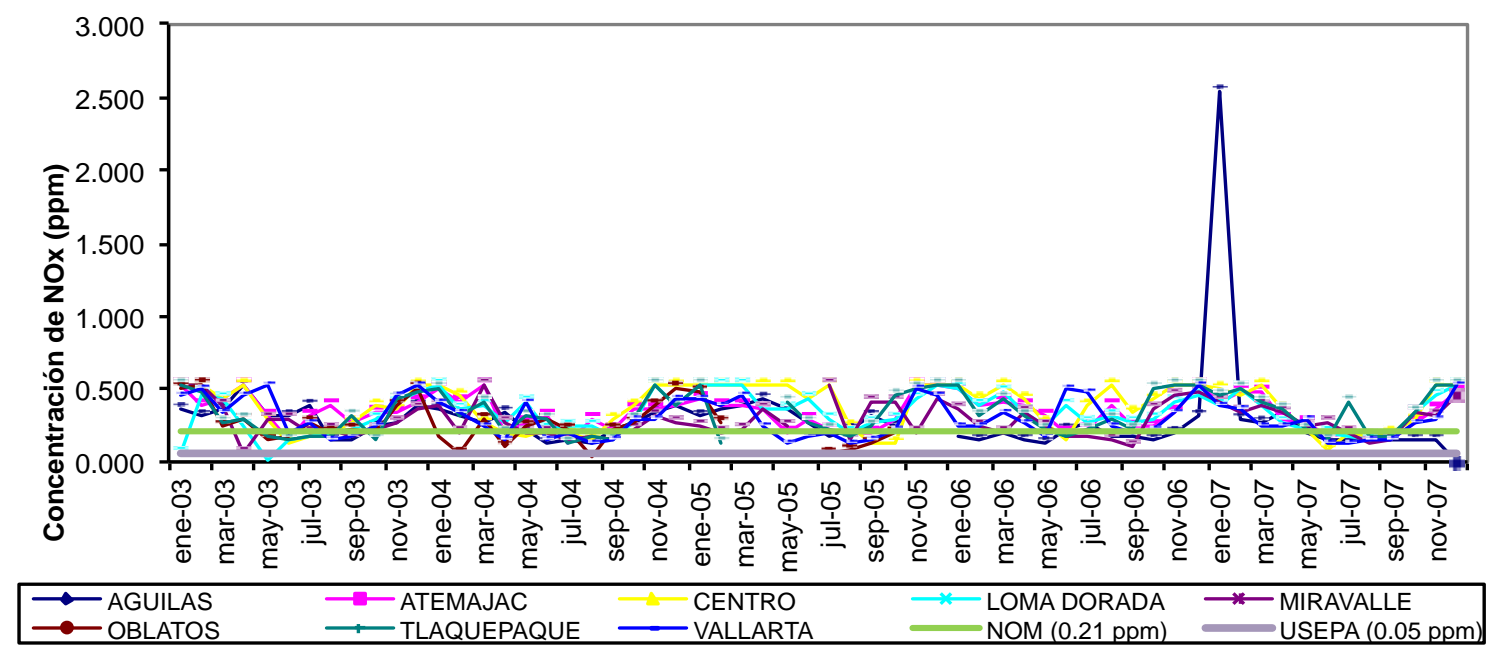

Figure 15. Time series of monthly averages of $\mathrm{NO}_{X}$ in the GMA. 


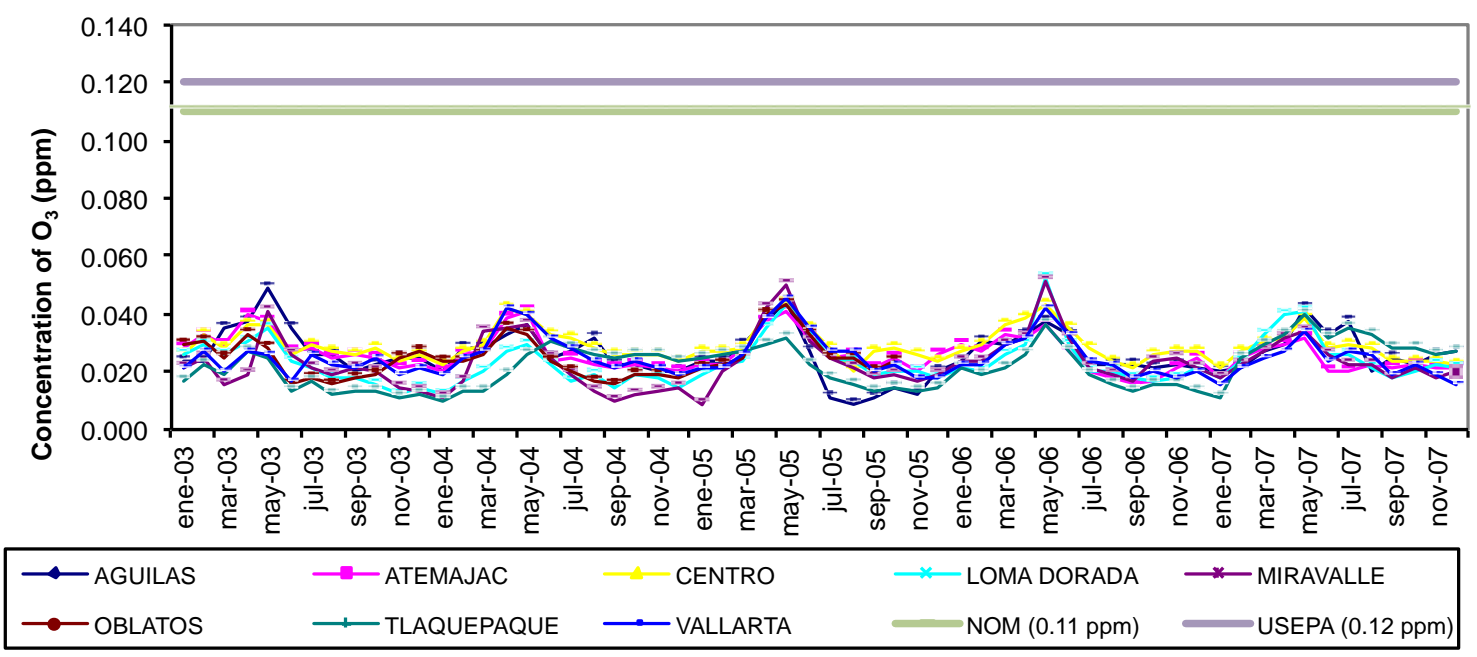

Figure 16. Time series of monthly averages of $\mathrm{O}_{3}$ in the GMA.

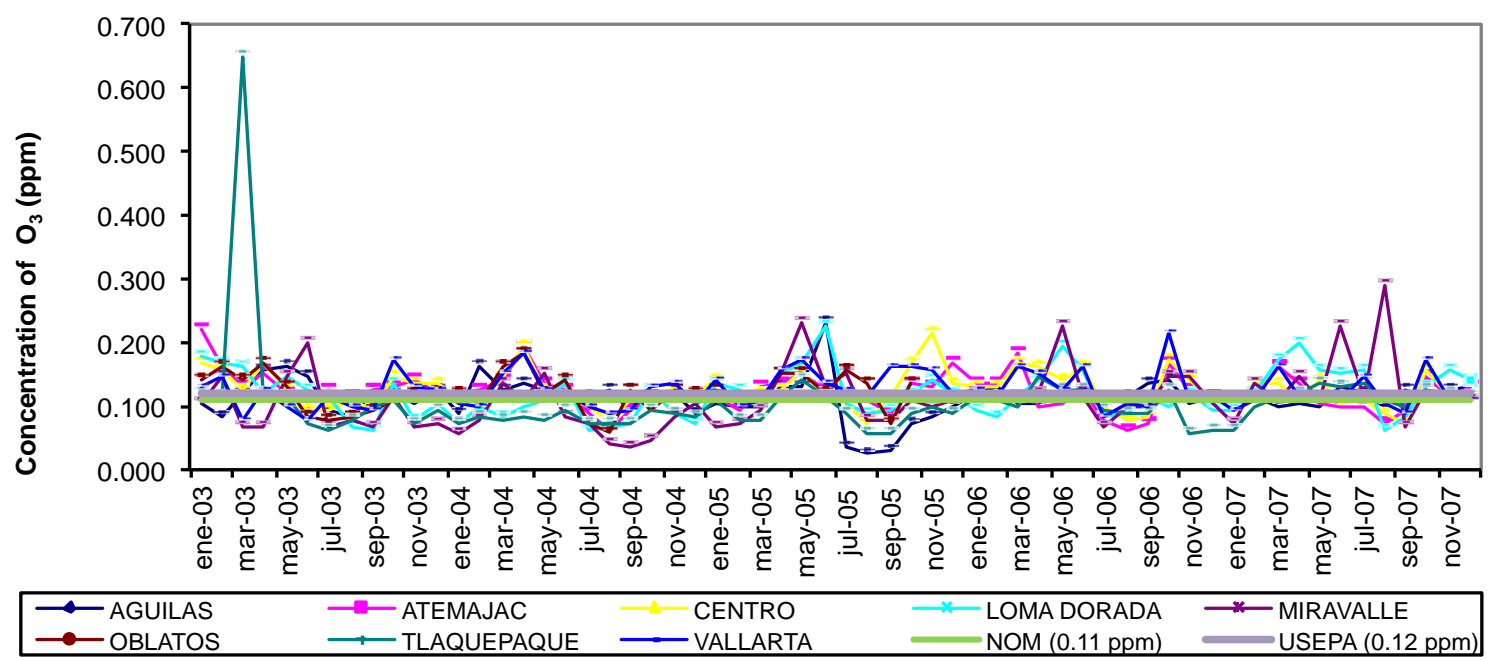

Figure 17. Time series of monthly maximum $\mathrm{O}_{3}$ in the GMZ.

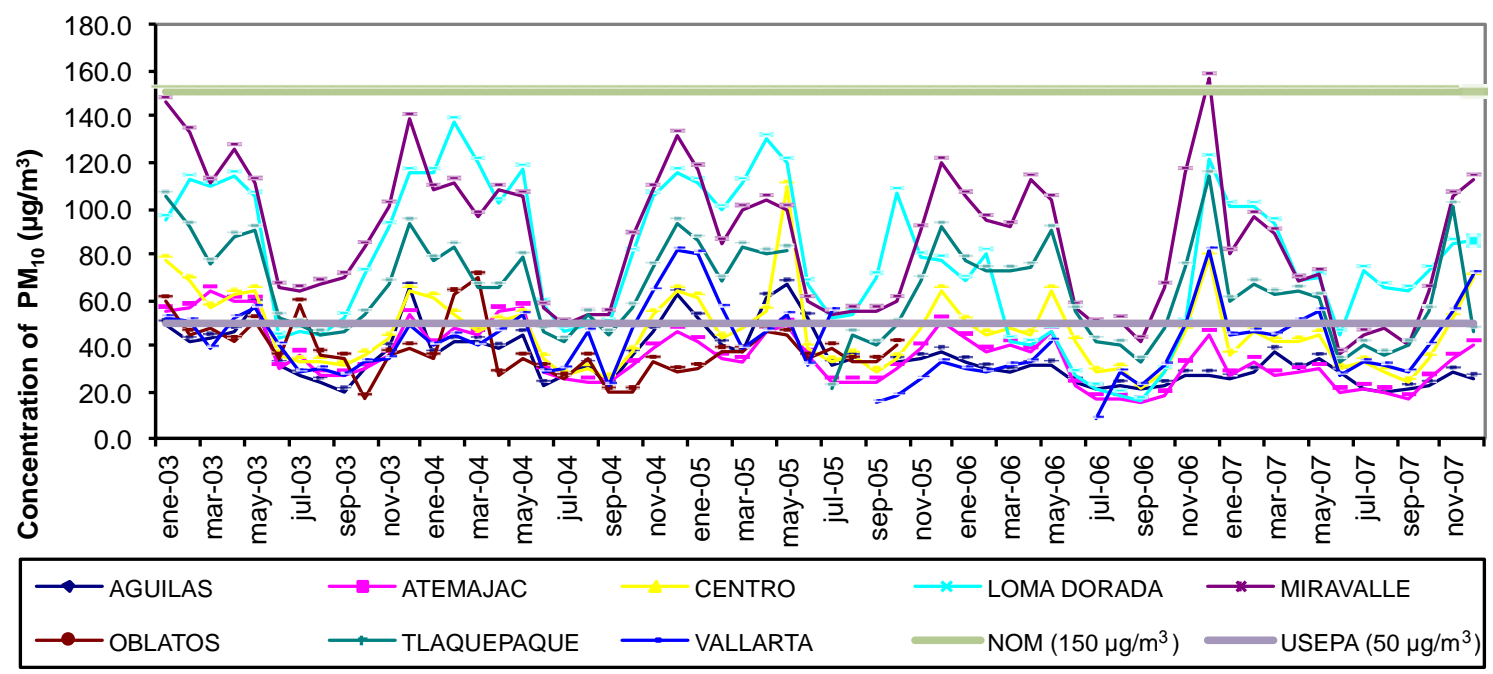

Figure 18. Time series of monthly averages of $P_{10}$ in the GMZ. 

Acute Respiratory Disease in the Guadalajara Metropolitan Zone, Jalisco, Mexico

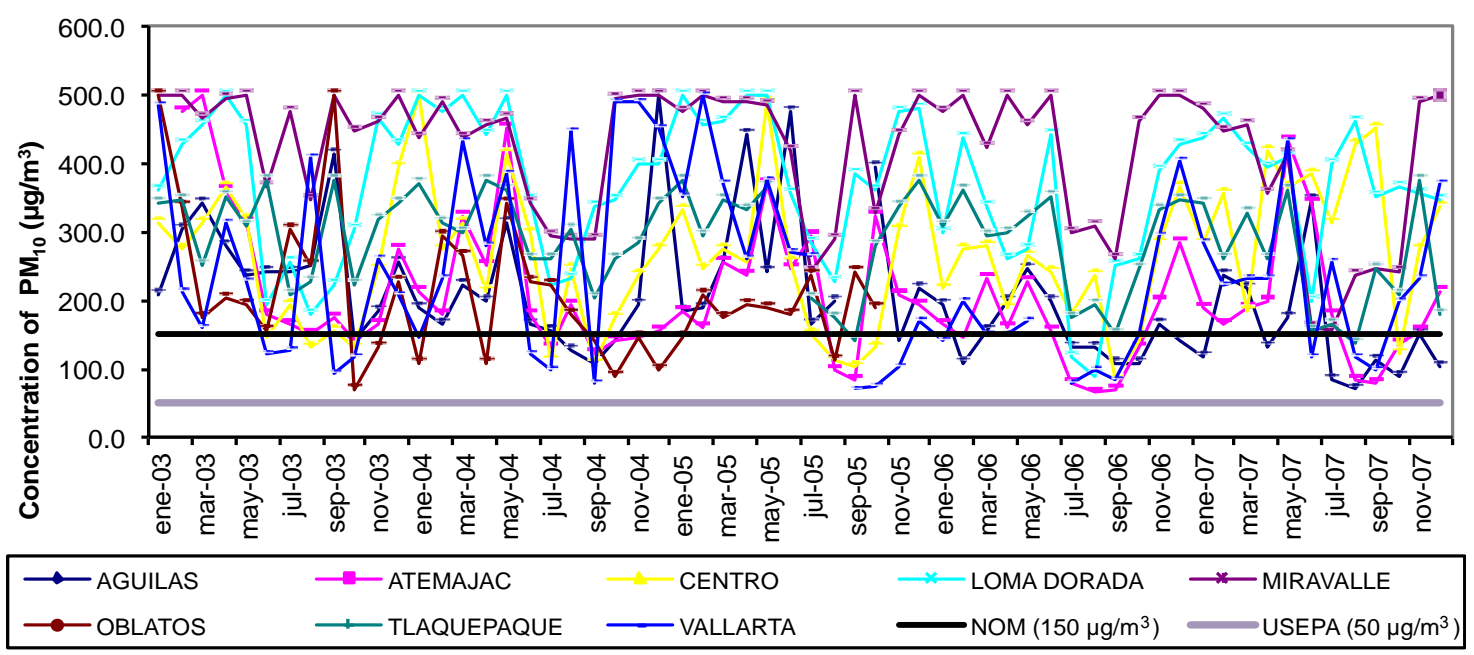

Figure 19. Time series of monthly averages of $P M_{10}$ in the $Z M G$.

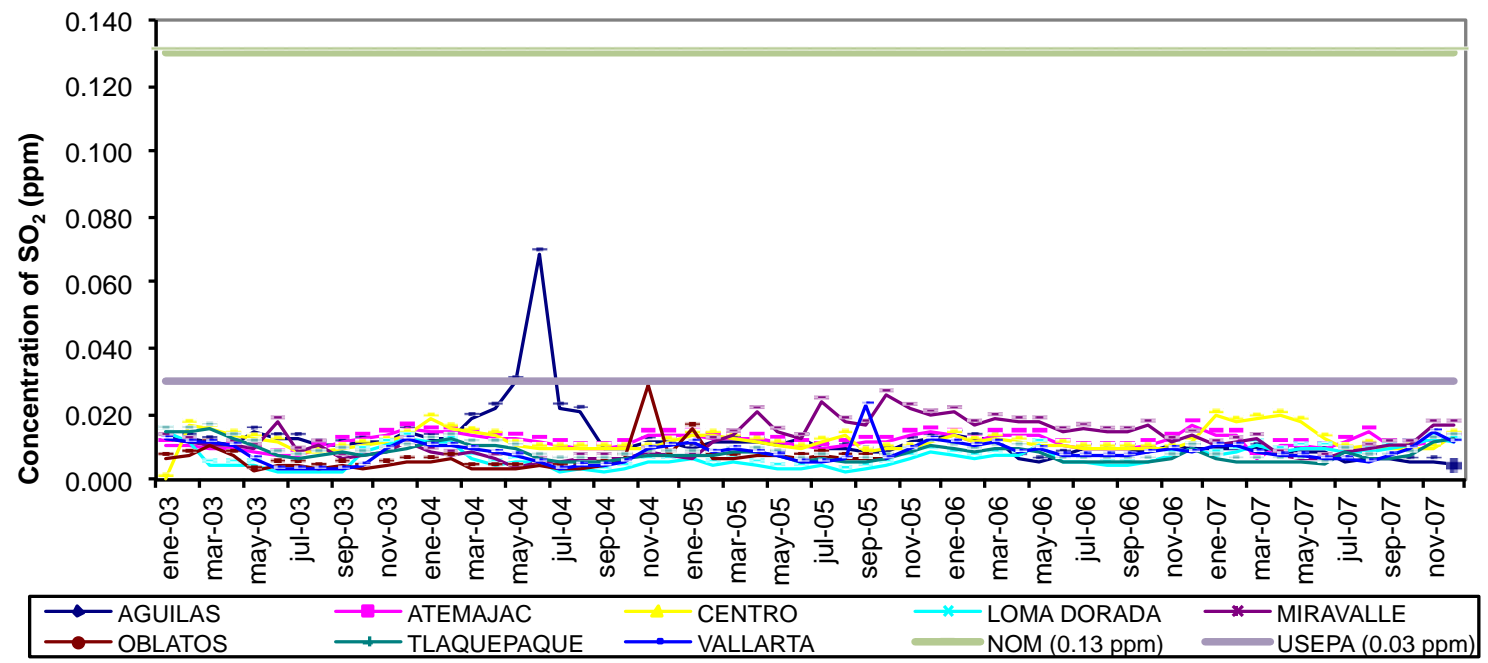

Figure 20. Time series of monthly averages of $\mathrm{SO}_{2}$ in the GMZ.

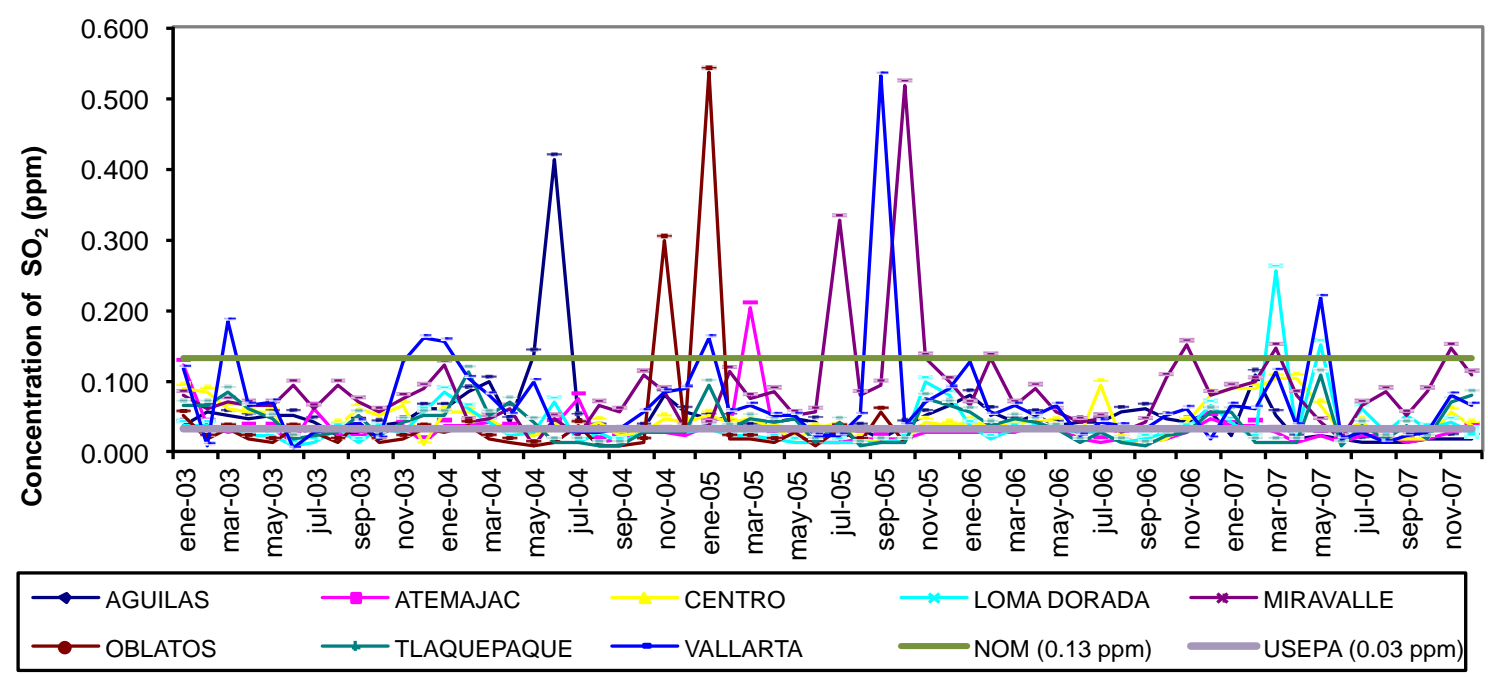

Figure 21. Time series of monthly averages of $\mathrm{SO}_{2}$ in the GMZ. 


\subsection{Acute Respiratory Diseases (ARD's) have a Higher Incidence in the GMZ from 2003 to 2007}

During the period 2003-2007 there were 1,067,551 ARD's consultations in children under five years, in public health institutions distributed as follows: in 2003 there were 258,068, 2004 242,225, 2005 216,513, 2006 198,446 and 2007 with 152,299 (Figure 22). Annual average was $213,510 \pm 41,209$ visits.

The conditions with the highest percentage are acute respiratory infections: acute nasopharyngitis, acute sinusitis, acute pharyngitis, acute laryngitis, acute traquitis, acute infections of the upper respiratory tract of multiple or unspecified sites, acute bronchitis and acute bronchiolitis with $98.0 \%$ of consultations, followed by pneumonia and bronchopneumonia with $1.1 \%$, asthma and status asthmaticus with $0.5 \%$ and streptococcal pharyngitis and streptococcal tonsillitis with $0.4 \%$.

The period with the highest number of inquiries by ARD's was from October to March, compared to the annual total (Figure 23). The most affected area was the southeast of the GMZ. The monthly trends show that the months of November, December, February and March are those with the highest percentage of respiratory diseases (Figure 23).

The distribution of medical unit shows that the medicine units and hospitals of IMSS (clinics 48 Circunvalación, 3418 de Marzo, 53 Zapopan, 3 Centro Médico, 92 Miravalle and 93 Tonalá,) were those that showed the greatest number of inquiries and are located in the southeast, south and central areas of the city matchingareas of higher air pollution (Figure 24).

\subsection{Correlations and Multivariate Analysis between TI, MV and AP vs. ARD's}

An analysis of the simple and multiple regression correlations, variance analysis (ANOVA) and t-student test of

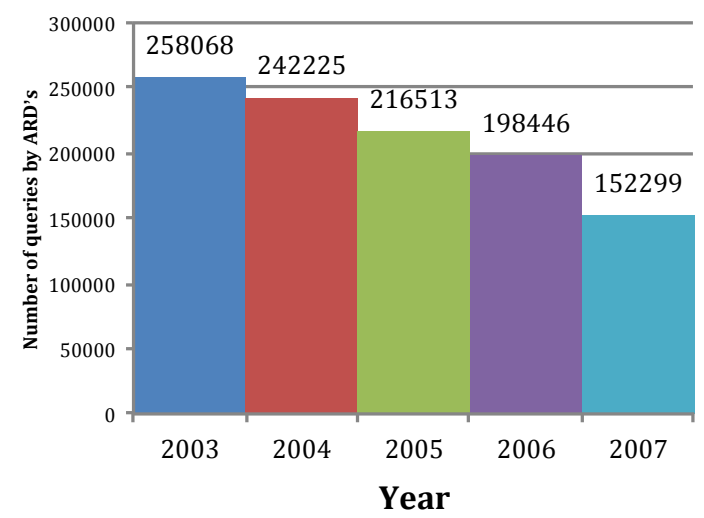

Figure 22. Distribution of annual consultations for ARDs in the GMZ.

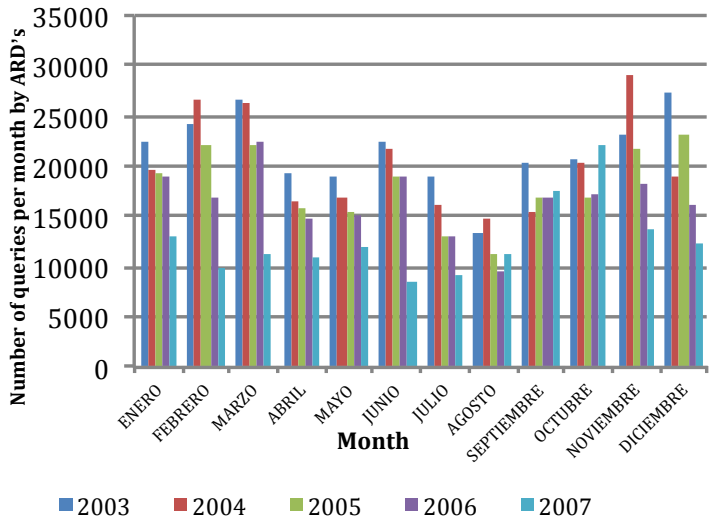

Figure 23. Distribution of monthly consultations for ARDs in the GMZ.

the acute respiratory diseases with TI, MV: temperature (Temp), relative humidity (RH), wind speed (WS) and wind direction (WD), and means, modes and monthly maximums of $\mathrm{AP}\left(\mathrm{CO}, \mathrm{SO}_{2}, \mathrm{NO}_{2}, \mathrm{NO}_{\mathrm{X}}, \mathrm{PM}_{10}\right.$ and $\left.\mathrm{O}_{3}\right)$ showed the highest significances for monthly averages, followed by the maximum and modes.

An approximation of the effects of TI, MV and the monthly average concentrations of AP that affect the health of the population of the GMZ are: temperature inversions (TI) showed significant correlation with the ARD's in three of the five years analyzed, the Temp in two years, the HR in two years, the WS in 3 years, the (WD) in two years, while $\mathrm{NO}_{\mathrm{X}}$ and $\mathrm{NO}_{2}$ pollutants showed significant correlation with ARD's throughout the period analyzed. $\mathrm{CO}$ and $\mathrm{SO}_{2}$ showed significance in two years. Meanwhile, $\mathrm{PM}_{10}$ and $\mathrm{O}_{3}$ showed significance in one year. Moreover, considering the presence of a variable related to the presence of others, which may enhance or counteract its effects (synergistic effect), in the case of $\mathrm{CO}, \mathrm{NO}_{2}, \mathrm{NO}_{\mathrm{x}}, \mathrm{O}_{3}, \mathrm{SO}_{2}$ and $\mathrm{PM}_{10}$, they show significant correlation with all variables in any of the five years analyzed. Similarly, the MV (Temp, RH, WS and WD) shows significant correlation with contaminants, and TI in any of the years analyzed.

\section{Conclusions and Discussion}

With respect to TI 2005, it showed the maximum average rate of $82.8 \%$, the average temperature gradient of $3.8^{\circ} \mathrm{C}$ and the maximum average thickness of $201 \mathrm{~m}$ with the average breaking time of 10:36 $\mathrm{h}$. The year 2007 had the highest percentage of moderate to heavy TI with $82.5 \%$. Throughout the period analyzed, the moderate and strong TI are the most common and are concentrated in the dry season months (November to May). February is the month of greatest frequency of TI.

Air pollutants have variable behavior during the year and between the years analyzed. It was evident that the 


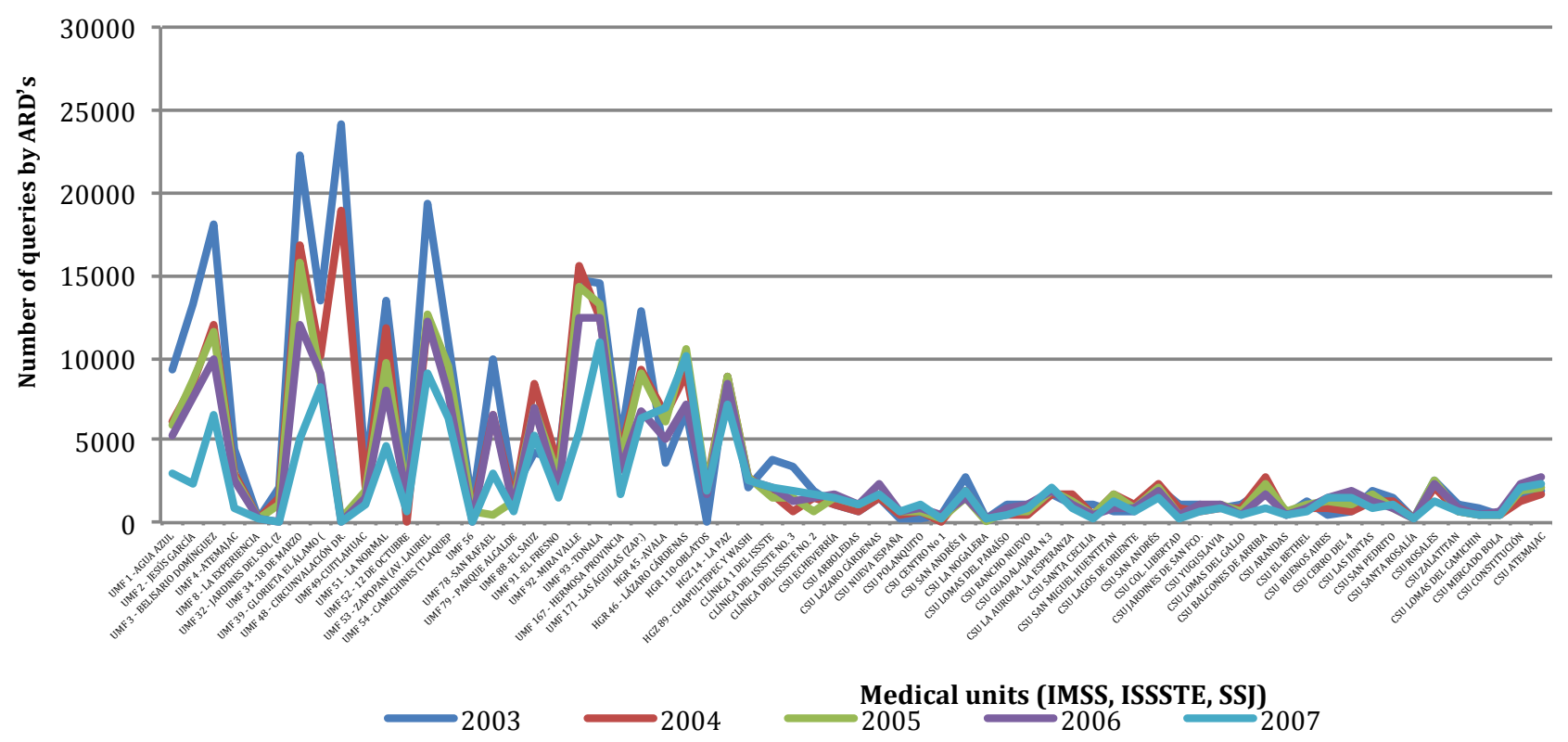

Figure 24. Distribution consultations of ARDs in different medical units in the GMZ.

contaminant found in greater concentration was $\mathrm{PM}_{10}$, followed by $\mathrm{O}_{3}, \mathrm{NO}_{2}, \mathrm{NO}_{\mathrm{X}}, \mathrm{CO}$ and $\mathrm{SO}_{2}$. The most affected areas are the southeast quadrant of the GMZ, which has the highest records in both its maximum, averages and modes. $\mathrm{CO}$ contamination in the GMZ is considered hazardous to health only when peaks occur. Concentrations of $\mathrm{NO}_{2}$ and $\mathrm{NO}_{\mathrm{X}}$ are important and represent a health risk to the population. $\mathrm{O}_{3}$ is moderate, however, exposure to high concentrations represents a health hazard. $\mathrm{PM}_{10}$ represent the main air pollutant of GMZ and are an important problem of environmental pollution and health risks of the population. $\mathrm{SO}_{2}$ was below standards and poses no risk to the health of the population. The most affected areas for AP are the southeast, south and center and at times they present extreme values in the rest of the GMZ.

As for the ARDs 2003 had the highest number of inquiries, the annual average in the period 2003-2007 was $213,510 \pm 41,209$ visits per year. The conditions with the highest percentages were acute respiratory infections $98.0 \%$, followed by pneumonia and bronchopneumonia with $1.1 \%$, asthma and status asthmaticus with $0.5 \%$ and streptococcal pharyngitis and tonsillitis with $0.4 \%$. The months that showed the greatest number of consultations for ARDs were from October to March, especially November, December, February and March. The distribution of disease per health care clinic demonstrates that 48 (Circunvalación), 34 (18 de Marzo), 53 (Zapopan), 3 (Centro Médico), 92 (Miravalle) y 93 (Tonalá) had the highest number of ARDs consultations, these areas are located in southeast, south and center of the city, and such areas coincide with higher levels of air pollutants.
A statistical analysis showed that TI showed significant correlation with the ARDs in three of the five years analyzed, the Temp in two years, HR in two years, three years WS, WD in two years, while the pollutants $\mathrm{NO}_{\mathrm{X}}$ and $\mathrm{NO}_{2}$ showed significant correlation with ARDs throughout the period analyzed. $\mathrm{CO}$ and $\mathrm{SO}_{2}$ showed significance in two years. Meanwhile, $\mathrm{PM}_{10}$ and $\mathrm{O}_{3}$ showed only one significant year.

It also emerged that a variable may be related to the presence of others, which may enhance or counteract its effects (synergistic effect), in the case of $\mathrm{CO}, \mathrm{NO}_{2}, \mathrm{NO}_{\mathrm{X}}$, $\mathrm{O}_{3}, \mathrm{PM}_{10}$ and $\mathrm{SO}_{2}$ they show a significant correlation with all the variables in the five years analyzed. Similarly, the MV (Temp, RH, WS and WD) correlates with the contaminants and TI in any of the years analyzed.

\section{REFERENCES}

[1] I. Romieu, J. Samet, K. Smith and N. Bruce, "Outdoor Air Pollution and Acute Respiratory Infections among Children in Developing Countries," Journal of Occupational \& Environmental Medicine, Vol. 44, No. 7, 2002, pp. 640649. doi:10.1097/00043764-200207000-00010

[2] L. T. Molina and M. J. Molina, "La Calidad del aire en la Megaciudad de México: Un Enfoque Integral," Fondo de Cultura Económica, México DF, 2005.

[3] B. J. Nebel and R. T. Wright, "Ciencias Ambientales. Ecología y Desarrollo Sostenible," Pearson-Prentice Hall, Estado de México, 1999.

[4] L. Hernández, A. Barraza, M. Ramírez, H. Moreno, P. Miller, L. Carbajal and R. Romieu, "Infant Morbidity Caused by Respiratory Diseases and Its Relation with the Air Pollution in Juarez City, Chihuahua, Mexico," Salud 
Pública de México, Vol. 49, No. 1, 2007, pp. 27-36.

[5] M. Romero, P. Bermejo, M. Lacasaña, M. Téllez, J. Aguilar and I. Romieu "Contaminación Atmosférica, Asma Bronquial e Infecciones Respiratorias Agudas en Menores de Edad de La Habana," Salud Pública de México, Vol. 46, No. 3, 2004, pp. 222-233. doi:10.1590/S0036-36342004000300012

[6] J. G. Henry and G. W. Heinke, "Ingeniería Ambiental," Prentice Hall, Estado de México, 1999.

[7] J. Martín, "Fundamentos de Climatología Analítica," Síntesis, Madrid, 1991.
[8] B. J. M. Alfaro, R. B. Limón, T. G. A. Martínez, G. M. M. Ramos, A. J. M. Reyes and M. G. Tijerina, "Ciencias del Ambiente," Grupo Editorial Patria, México DF, 2008.

[9] G. Miller, "Ciencia Ambiental. Desarrollo Sostenible. Un Enfoque Integral," Thomson Editores, México DF, 2007.

[10] H. Ramírez, M. Andrade, M. González and A. Celis, "Air Pollutants and Their Correlation with Medical Visits for Acute Respiratory Infections in Children Less than Five Years of Age in Urban Guadalajara, Mexico," Salud Pública de México, Vol. 48, No. 5, 2006, pp. 385-394. doi:10.1590/S0036-36342006000500005 